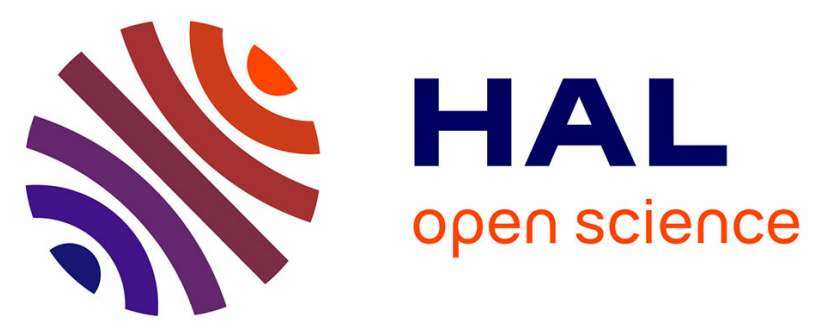

\title{
Modelling and Robust Position/Force Control of a Piezoelectric Microgripper.
}

Micky Rakotondrabe, Cédric Clévy, Philippe Lutz

\section{To cite this version:}

Micky Rakotondrabe, Cédric Clévy, Philippe Lutz. Modelling and Robust Position/Force Control of a Piezoelectric Microgripper.. Third Annual IEEE Conference on Automation Science and Engineering, CASE'2007., Sep 2007, Scottsdale, Arizona, United States. sur CD ROM - 6 p. hal-00182296

\section{HAL Id: hal-00182296 https://hal.science/hal-00182296}

Submitted on 25 Oct 2007

HAL is a multi-disciplinary open access archive for the deposit and dissemination of scientific research documents, whether they are published or not. The documents may come from teaching and research institutions in France or abroad, or from public or private research centers.
L'archive ouverte pluridisciplinaire HAL, est destinée au dépôt et à la diffusion de documents scientifiques de niveau recherche, publiés ou non, émanant des établissements d'enseignement et de recherche français ou étrangers, des laboratoires publics ou privés. 


\title{
Modelling and Robust Position/Force Control of a Piezoelectric Microgripper
}

\author{
Micky Rakotondrabe, Cédric Clévy and Philippe Lutz
}

\begin{abstract}
This paper deals with the control of a piezoelectric microgripper based on two piezocantilevers. To avoid the destruction of the manipulated micro-object and to permit a high accurate positioning, the microgripper is controlled on position and on force. Each piezocantilever is separately modelled and controlled: while the one is controlled on position, the second is controlled on force. Because the models are subjected to uncertainties and the micromanipulation requires good performances, a $H_{\infty}$ robust controller is designed for each system. The experiments end the paper and show that good performances are obtained.
\end{abstract}

\section{INTRODUCTION}

In micromanipulation, i.e. manipulation of object from $1 \mu \mathrm{m}$ to $1 \mathrm{~mm}$ sizes, the required accuracy is generally sub-micrometric. Instead of hinges, active materials are used to design systems for micromanipulation. In fact, hinges are characterized by frictions and may decrease the performances (accuracy) of the micromanipulation. Among these active materials, piezoelectric materials are widespread because of their fast response time and their high resolution. One of the main applications of piezoelectric materials in microsystems is piezoelectric microgrippers. A piezoelectric microgripper is based on two piezoelectric cantilevers (piezocantilevers). It is used to pick a micro-object, transport and place it with a high positioning accuracy. Nevertheless, to avoid the destruction of the micro-object, a control of the manipulation force is necessary.

In the litterature, many studies have been done on the modelling and control of a piezocantilever but few concern a whole microgripper. The majority of these studies especially refer to the deflection of the cantilever: [1] is an example in the linear approach while [2][3][4][5] takes into account the nonlinearities of the material. On the other hand, the control of the force is today a partially solved problematic because it requires the integration of a very small sensor, the use of the piezoelectric properties or a compliant structure. Up to now, very few solutions are proposed: [6][7][8].

In this paper, we propose to model and control a piezoelectric microgripper. In order to ensure good performances for the micromanipulation, a $H_{\infty}$ robust con-

Laboratoire d'Automatique de Besançon LAB CNRS UMR6596

ENSMM - Université de Franche-Comté

24, rue Alain Savary

25000 Besançon - France

\{mrakoton, cclevy,plutz\}@ens $2 m$.fr troller is used. The position (directly measured) and the manipulation force (estimated) are considered as the references. The paper is organized as follows. First, the modelling of the microgripper is presented. Then, the design of the $H_{\infty}$ controller for each piezocantilever is presented. Finally, the experimental results are presented and discussed.

\section{Modelling}

Let the Fig. 1 present the piezoelectric microgripper manipulating a micro-object. In this figure, $F_{m}$ is the manipulation force applied by the two piezocantilevers to the micro-object. Our objective is to control the position of the micro-object by means of one piezocantilever and to maintain a constant value of $F_{m}$ by means of the second piezocantilever. Because the adhesion forces [9] are insignificant relative to the manipulation force range of our concern (more than millinewton), and because we experiment objects from $500 \mu \mathrm{m}$ to $1.5 \mathrm{~mm}$ in size, they will not be taken into account in this paper.

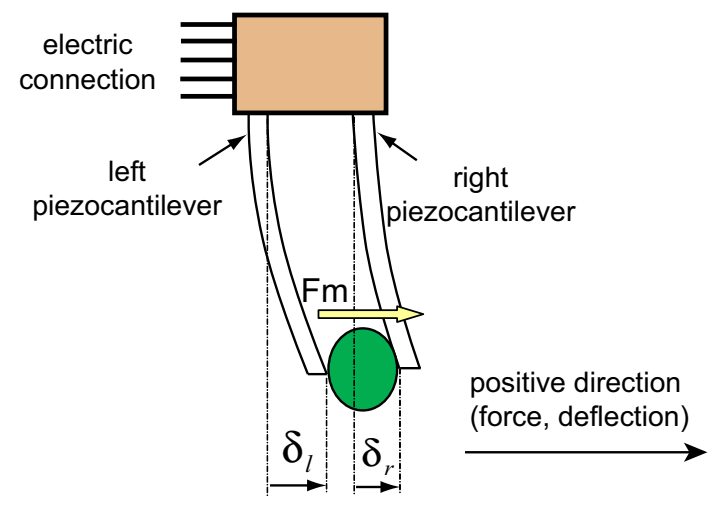

Fig. 1. A piezoelectric microgripper manipulating a micropart.

The relation between the applied voltage $U_{i}$, the force $F_{i}$ applied to the piezocantilever at its tip and the resulting deflection $\delta_{i}$, with $i \in\{l, r\}$, in the static mode is $[10]$ :

$$
\delta_{i}=d_{i} \cdot U_{i}+s_{i} \cdot F_{i}
$$

where $d_{i}>0$ is the equivalent piezoelectric constant of the piezocantilever and $s_{i}>0$ is the equivalent elastic constant.

However, it has been shown that the transient part of the $\left(U_{i}, \delta_{i}\right)$-transfer and the transient part of the $\left(F_{i}, \delta_{i}\right)$ transfer of a piezocantilever are similar [11]. Thus, we have: 


$$
\delta_{i}=\left(d_{i} \cdot U_{i}+s_{i} \cdot F_{i}\right) \cdot D_{i}(s)
$$

where $D_{i}(s)$ (such as $D_{i}(0)=1$ ) represents the dynamic part and $s$ the Laplace variable.

On the other hand, the relation between the manipulation force $F_{m}$ and the contraction of the micro-object is:

$$
\left(\delta_{l}-\delta_{l 0}\right)-\left(\delta_{r}-\delta_{r 0}\right)=s_{o} \cdot D_{o}(s) \cdot F_{m}
$$

where $s_{o}>0$ is the elastic constant of the micro-object, $D_{o}(s)$ (such as $D_{i}(0)=1$ ) is its dynamic characteristic and $\delta_{l 0}$ and $\delta_{r 0}$ are the deflections of the left and right piezocantilevers before touching the object (Fig. 2).

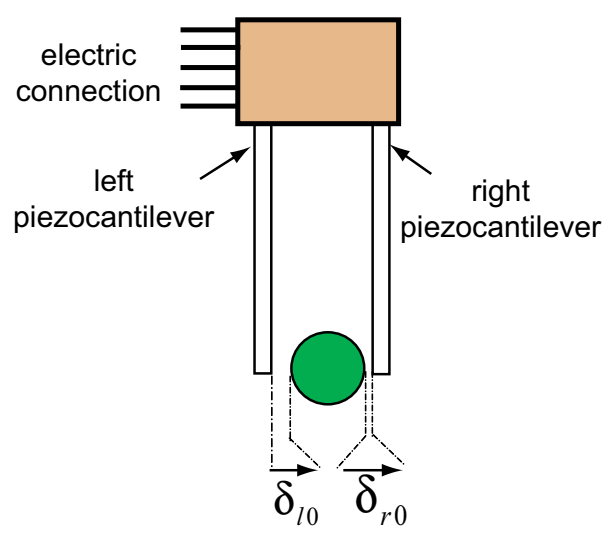

Fig. 2. Initial situation: the micro-object is not in contact with the piezocantilevers.

Noting $\Delta \delta=\delta_{l 0}-\delta_{r 0}$ and replacing $F_{l}=F_{r}=-F_{m}$ in the (Eq. 2), we have:

$$
\left\{\begin{array}{l}
\delta_{l}=\left(d_{l} \cdot U_{l}-s_{l} \cdot F_{m}\right) \cdot D_{l}(s) \\
\delta_{r}=\left(d_{r} \cdot U_{r}-s_{r} \cdot F_{m}\right) \cdot D_{r}(s) \\
\left(\delta_{l}-\delta_{r}\right)-\Delta \delta=s_{o} \cdot D_{o}(s) \cdot F_{m}
\end{array}\right.
$$

Without loss of generality, we choose the left piezocantilever for the force $F_{m}$ actuation while the right one for the micro-object position actuation. From the set of equations (Eq. 4), two approaches are possible to model the microgripper:

- the first approach uses one bivariable system where the inputs are the two voltages and the outputs are the deflection $\delta_{r}$ and the force $F_{m}$. It takes into account the effects of the piezocantilevers deflections to each other. So, it is possible to design a multivariable controller leading to very good performances. However, this approach needs a precise model,

- the second approach consists in modelling independently the two piezocantilevers. While the one is modelled on force, the second is modelled on deflection. The advantage is that the two models are easier than of the first approach. However, since the deflection of one cantilever disturbs that of the other, and vice versa, the design of each feedback controller should takes into account such disturbances.
In both approaches, the models are dependent on the characteristics of the micro-object. In this paper, we choose the second approach because of the simplicity of the models and of the issued controllers.

\section{A. Model of the voltage/deflection transfer}

Here, we model the right piezocantilever. From the second equation of the set (Eq. 4), we have the nominal model:

$$
\delta_{r}=d_{r} \cdot D_{r}(s) \cdot\left(U_{r}+b_{r}\right)
$$

where $b_{r}=-\frac{s_{r} \cdot F_{m}}{d_{r}}$ is an input disturbance to be rejected. Fig. 3 shows the corresponding scheme.

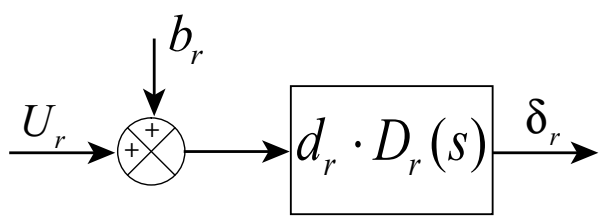

Fig. 3. Scheme of the nominal model of the right piezocantilever.

\section{B. Model of the voltage/force transfer}

The left piezocantilever is modelled in this part. From the first and last equations of the set (Eq. 4), we have:

$$
F_{m}=\frac{1}{\left(s_{o}+s_{l}\right)} \cdot D_{k}(s) \cdot\left(d_{l} \cdot D_{l}(s) \cdot U_{l}-\delta_{r}-\Delta \delta\right)
$$

with:

$$
D_{k}(s)=\frac{\left(s_{o}+s_{l}\right)}{\left(D_{o}(s)+D_{l}(s)\right)}
$$

and $D_{k}(0)=1$.

The (Eq. 6) clearly shows that the model depends on the characteristics of the micro-object. Nevertheless, it is not practical to identify the model and to synthesize a controller at each change of manipulated micro-object. Thus, we propose to have a nominal model independent of the micro-object characteristics, i.e. $s_{o}=0$ and $D_{k}(s)=1$, and use a robust controller to ensure the stability and the performances. Such hypothesis will be verified in the experimental results. Finally, we have the following nominal model:

$$
F_{m}=\frac{d_{l}}{s_{l}} \cdot D_{l}(s) \cdot U_{l}+F_{\text {pert }}
$$

where $F_{\text {pert }}=-\frac{\left(\delta_{r}+\Delta \delta\right)}{s_{l}}$ is an output disturbance to be rejected. Fig. 4 shows the corresponding scheme. 


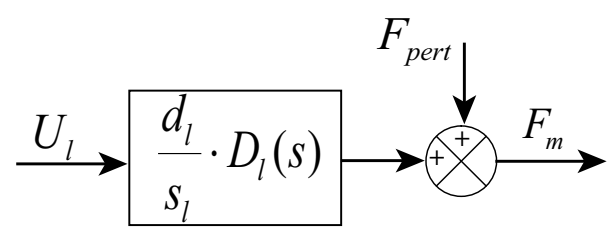

Fig. 4. Scheme of the nominal model of the left piezocantilever.

\section{Identification}

For our experiments, we use two unimorph piezocantilevers based on a PIC151 piezolayer [12] and a Copper layer. The sizes of each piezocantilever are: $15 \mathrm{~mm} \times$ $2 \mathrm{~mm} \times 0.3 \mathrm{~mm}$ (length, width and thickness) where the thickness of the piezolayer is $0.2 \mathrm{~mm}$. The experimental setup (Fig. 5) is made up of:

- the microgripper,

- two laser sensors (Keyence sensor with 500nm of accuracy) to measure the deflections of the piezocantilevers,

- an amplifier with two lines for $U_{l}$ and $U_{r}$,

- a computer-DSpace material to acquire the measurements and to generate the input voltages $U_{l}$ and $U_{r}$.
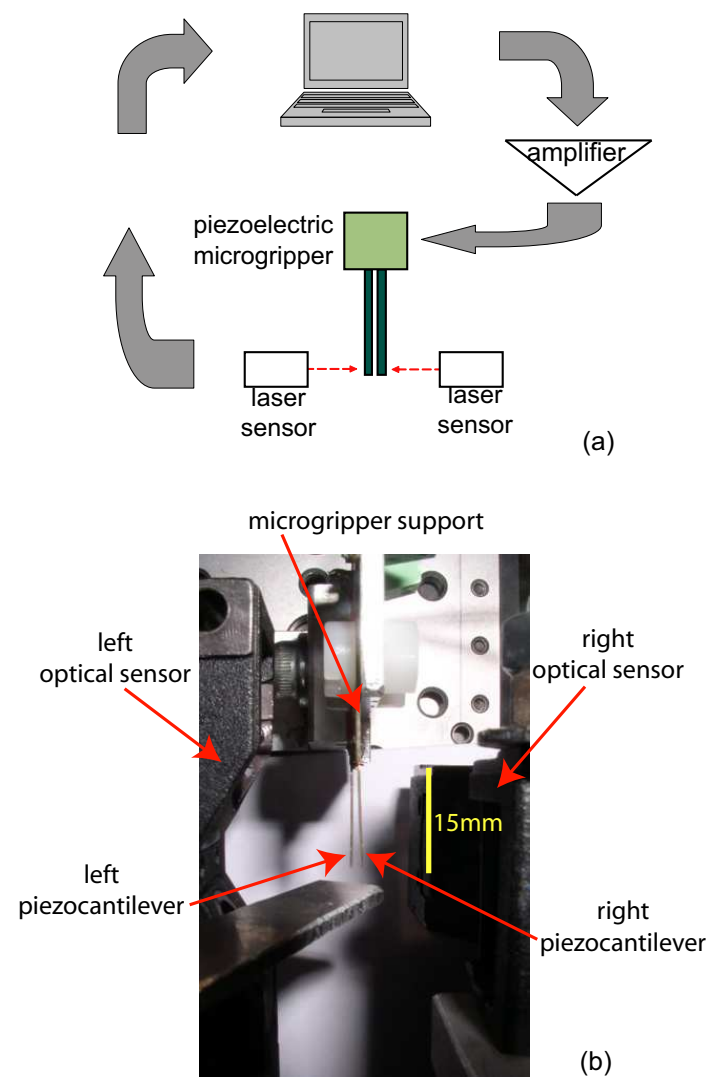

Fig. 5. Experimental setup.

For each piezocantilever, a harmonic experiment was performed. Afterwards, the $\left(U_{i}, \delta_{i}\right)$-transfer function is identified in the frequenty domain. A second order model is assumed to be sufficient for piezocantilevers [13]. We have:

$$
\left\{\begin{array}{l}
d_{r}=0.545\left[\frac{\mu m}{V}\right] \\
D_{r}(s)=\frac{1}{1.86 \times 10^{-8} \cdot s^{2}+4.1 \times 10^{-6} \cdot s+1}
\end{array}\right.
$$

and

$$
\left\{\begin{array}{l}
d_{l}=0.525\left[\frac{\mu m}{V}\right] \\
D_{l}(s)=\frac{1}{1.85 \times 10^{-8} \cdot s^{2}+2.72 \times 10^{-6} \cdot s+1}
\end{array}\right.
$$

Fig. 6 shows the results of $\left(U_{i}, \delta_{i}\right)$-transfer function for the right piezocantilever.

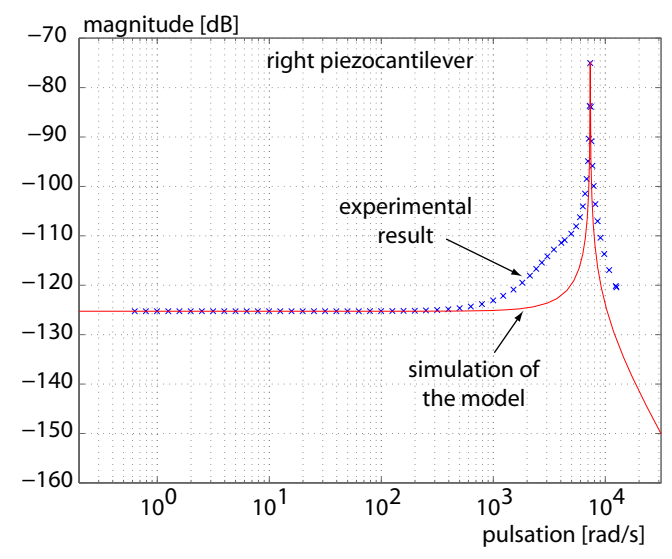

Fig. 6. Magnitude of the right piezocantilever.

Finally, to identify the elastic constant $s_{i}$, a mass is hung on at the tip of each piezocantilever and the resulting deflection is measured. We have $s_{r}=s_{l}=$ $1.931 \times 10^{-3}\left[\frac{m}{N}\right]$.

Because the characteristics of the micro-object have been neglected in the nominal model, the latter is subjected to uncertainties. Such approach let us avoid the model identification and the controller synthesis of at each change of micro-object. Therefore, we choose a robust controller to ensure the stability and performances robustness face to the uncertainties, we use the $H_{\infty}$ controllers. Moreover, the disturbance rejection will be taken into account during the controller design.

\section{Control of the deflection $\delta_{r}$}

Let the Fig. 7 be the closed-loop scheme. In the figure, $\delta_{r}^{r}$ indicates the reference input. Two weighting functions are used: $W_{1}^{r}$ for the closed-loop performances and $W_{2}^{r}$ for the disturbance rejection.

\section{A. Standard form}

Let $P_{r}(s)$ be the augmented system including the nominal system and the weighting functions. Fig. 8 shows the corresponding standard scheme.

The standard $H_{\infty}$ problem consists in finding an optimal value $\gamma>0$ and a controller $K_{i}(s)$ stabilizing the closed-loop scheme of the Fig. 8 and guaranteeing the following inequality [14]: 


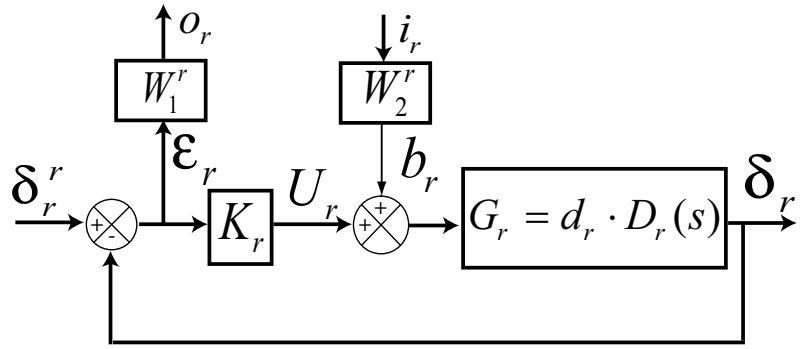

Fig. 7. The closed-loop scheme with the weighting functions.

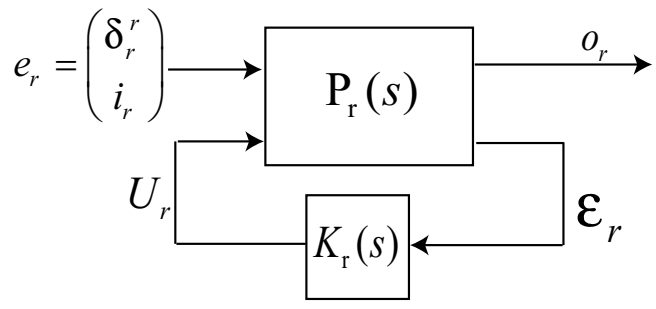

Fig. 8. The standard form.

$$
\left\|F_{\text {low }}\left(P_{i}(s), K_{i}(s)\right)\right\|_{\infty}<\gamma
$$

where $F_{\text {low }}(.,$.$) is the lower Linear Fractionar Transfor-$ mation and is defined here by $F_{\text {low }}\left(P_{r}(s), K_{r}(s)\right)=\frac{o_{r}(s)}{e_{r}(s)}$.

From the Fig. 7, we have:

$$
o_{r}=W_{1}^{r} \cdot S_{r} \cdot \delta_{r}^{r}-W_{1}^{r} \cdot S_{r} \cdot G_{r} \cdot W_{2}^{r} \cdot i_{r}
$$

where $S_{r}=\left(1+K_{r} \cdot G_{r}\right)^{-1}$ is the sensitivity function. Using the condition (Ineq. 11) and the (Eq. 12), we infer:

$$
\begin{gathered}
\left\|W_{1}^{r} \cdot S_{r}\right\|_{\infty}<\gamma \\
\left\|W_{1}^{r} \cdot S_{r} \cdot G_{r} \cdot W_{2}^{r}\right\|_{\infty}<\gamma
\end{gathered} \Leftrightarrow \quad \begin{gathered}
\left|S_{r}\right|<\frac{\gamma}{\left|W_{1}^{r}\right|} \\
\left|S_{r} \cdot G_{r}\right|<\frac{W_{1}^{r} \cdot W_{2}^{r} \mid}{\left.\mid W^{2}\right)}
\end{gathered}
$$

To solve the problem (Ineq. 13), we use the GloverDoyle algorithm which is based on the Riccati equations [15][16]. The issued controller $K_{r}$ is robust in the fact that it ensures the stability and the performances even if the nominal system $G_{r}$ has an uncertainty relative to the real plant. The wanted performances are introduced through the weighting functions.

\section{B. Choice of the weighting functions}

The transfer functions $\frac{1}{W_{1}^{r}}$ and $\frac{1}{W_{1}^{r} \cdot W_{2}^{r}}$ are chosen from the specifications respectively on the tracking performances and on the disturbance rejection. Thus, the weighting functions $W_{1}^{r}$ and $W_{2}^{r}$ can be automatically deduced. The specifications are:

- the maximal response time is $100 \mathrm{~ms}$,

- the overshoot is null,

- the maximal statical error is $0.1 \%$,

- finally, the rejection of the disturbance is a highpass filter with a cutting frequency more than $50 \mathrm{~Hz}$.
When the disturbance is a static force, its influence on the deflection has been chosen to be lower than $1.7\left[\frac{\mu m}{10 m N}\right]$.

From the performances specifications, we choose:

$$
\frac{1}{W_{1}^{r}}=10^{-3} \cdot \frac{3 \cdot s+1}{30 \times 10^{-3} \cdot s+1}
$$

Using the specifications on the disturbance rejection and using the equivalence $b_{r}=-\frac{s_{r} \cdot F_{m}}{d_{r}}$, we choose:

$$
\frac{1}{W_{1}^{r} \cdot W_{2}^{r}}=0.5 \times 10^{-7} \cdot \frac{3 \cdot s+1}{3 \times 10^{-3} \cdot s+1}
$$

\section{Calculation of the controller}

The computed controller has an order of 5 . To minimize the memory and time consumptions in the computer, the controller order has been reduced to 2 using the balanced realization technique [17]. We obtain:

$$
\left\{\begin{array}{l}
\gamma^{o p t}=10.1 \\
K_{r}=\frac{-15810 \cdot\left(s+4 \times 10^{6}\right) \cdot\left(s-1.4 \times 10^{4}\right)}{\left(s+1.5 \times 10^{7}\right) \cdot(s+0.3)}
\end{array}\right.
$$

\section{Control of the force $F_{m}$}

Fig. 9 shows the closed-loop scheme. In the figure, $F_{m}^{r}$ indicates the reference input. Two weighting functions are used: $W_{1}^{l}$ for the closed-loop performances and $W_{2}^{l}$ for the output disturbance rejection.

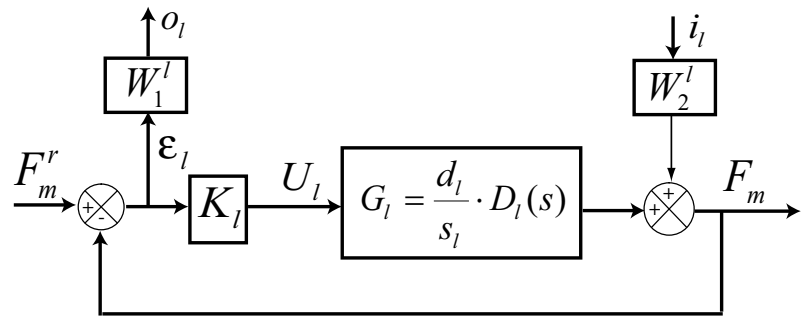

Fig. 9. The closed-loop scheme with the weighting functions.

From the Fig. 9, we have:

$$
o_{l}=W_{1}^{l} \cdot S_{l} \cdot F_{m}^{r}-W_{1}^{l} \cdot S_{l} \cdot W_{2}^{l} \cdot i_{l}
$$

where $S_{l}=\left(1+K_{l} \cdot G_{l}\right)^{-1}$ is the sensitivity function. Using the condition (Ineq. 11) and the (Eq. 17), we infer:

$$
\begin{gathered}
\left\|W_{1}^{l} \cdot S_{l}\right\|_{\infty}<\gamma \\
\left\|W_{1}^{l} \cdot S_{l} \cdot W_{2}^{l}\right\|_{\infty}<\gamma
\end{gathered} \Leftrightarrow \quad \begin{gathered}
\left|S_{l}\right|<\frac{\gamma}{\left|W_{1}^{l}\right|} \\
\left|S_{l}\right|<\frac{\gamma}{\left|W_{1}^{l} \cdot W_{2}^{l}\right|}
\end{gathered}
$$




\section{A. Choice of the weighting functions}

The following specifications are used:

- in order to maintain the micro-object during the positioning, the response time in force should be faster than the one of the deflection. For that, we choose a response time equal to $10 \mathrm{~ms}$,

- the overshoot is null,

- the maximal statical error is $1 \%$,

- finally, the rejection of the disturbance is a highpass filter with a cutting frequency is $5 \mathrm{~Hz}$. Such a value is chosen because the disturbance, which is the deflection of the other piezocantilever, has a low bandwidth (response time). When the disturbance is a static deflection, its influence on the output must be lower than $0.2\left[\frac{m N}{40 \mu m}\right]$.

From the performances specifications, we choose:

$$
\frac{1}{W_{1}^{r}}=10^{-2} \cdot \frac{3 \cdot s+1}{3 \times 10^{-3} \cdot s+1}
$$

Using the specifications of the disturbance rejection and using the equivalence $F_{\text {pert }}=-\frac{\left(\delta_{r}+\Delta \delta\right)}{s_{l}}$, we choose:

$$
\frac{1}{W_{1}^{r} \cdot W_{2}^{r}}=10^{-2} \cdot \frac{3 \cdot s+1}{30 \times 10^{-3} \cdot s+1}
$$

\section{B. Calculation of the controller}

The computed controller has an order of 5 . Once again, the controller order has been reduced. We obtain:

$$
\left\{\begin{array}{l}
\gamma^{\text {opt }}=1.02 \\
K_{l}=\frac{0.06 \cdot\left(s+7.3 \times 10^{8}\right) \cdot\left(s^{2}+277 \cdot s+8.2 \times 10^{7}\right)}{\left(s+1.2 \times 10^{6}\right) \cdot\left(s+1.9 \times 10^{4}\right) \cdot(s+0.3)}
\end{array}\right.
$$

\section{EXPERIMENTAL RESUlTS}

The two controllers given by the (Eq. 16) and the (Eq. 21) have been implemented to a computer-DSpace real-time material. The Matlab-Simulink and the ControlDesk softwares were used for that. Since there is no adequate force sensor, a force estimator has been used [1]. Fig. 10 shows the principle scheme of the experiments.

Experiments with two types of micro-object were performed (Fig. 11): a flexible material (polystyrene) and a rigid material (rigid plastic). The sizes of the microobjects were chosen so that $\Delta \delta \approx 0$. Its width, corresponding to the gap between the two piezocantilevers, is nearly $1 \mathrm{~mm}$.

The results show that the same performances are obtained for both. Fig. 12 presents the experimental results with the rigid plastic mini gear. Initially, the deflection and the force are null. Then, a manipulation force reference of $5 \mathrm{mN}$ is applied. A small effect is seen on the deflection $(t=1.3 \mathrm{~s})$ but is quickly rejected. Between $t=2 s$ and $t=5 \mathrm{~s}$, a series of positive and negative steps (amplitude: $20 \mu \mathrm{m}$ ) in position reference is applied. As we can see, its influence on the force is also quickly rejected despite the high amplitude of the

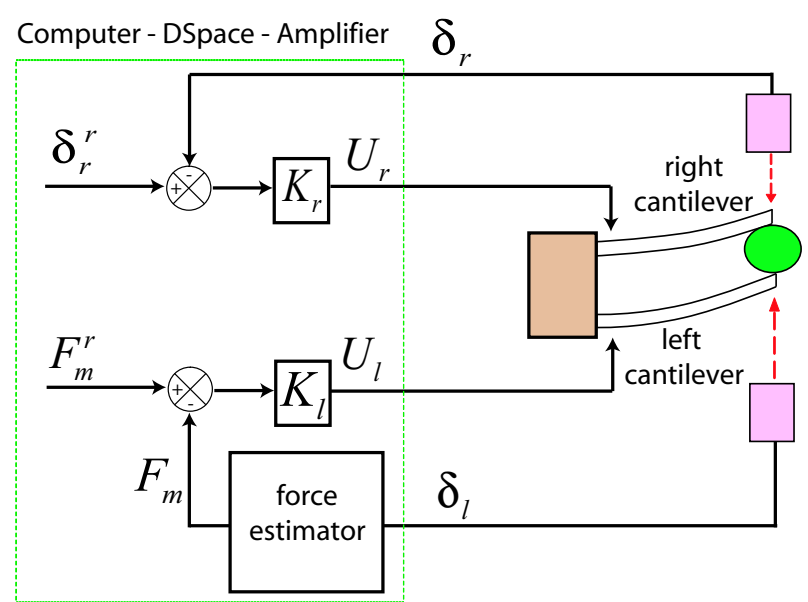

Fig. 10. Principle scheme of the microgripper control.

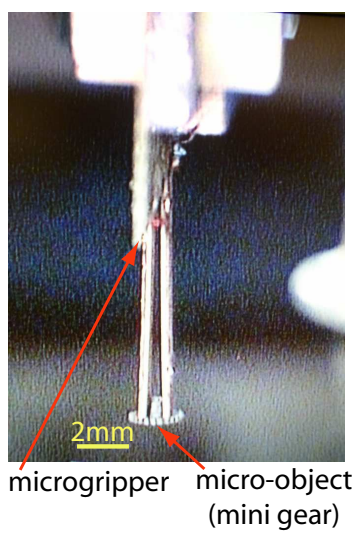

Fig. 11. The microgripper manipulating a mini gear (in rigid plastic).

diturbance effect. Finally $(t=5.8 s)$, the manipulation force reference is set to zero. Since the size of the microobject is equal to the gap of the microgripper, a negative deflection reference should be applied to release it. On the other hand, we can remark that the accuracy is very high for the deflection and for the force. In fact, the static errors are very small and are not visible by the sensors.

In order to evaluate the response time, we zoom in the step reponse of each output (Fig. 13). It can be seen that the response time is exceeded: $t_{\text {resp }} \approx 250 \mathrm{~ms}$ for the deflection and $t_{\text {resp }} \approx 150 \mathrm{~ms}$ for the force. This is explained in the fact that the optimal value of $\gamma$ is high for the deflection. For all that, the force response time still stays lower than the one of the deflection and the general performances are always suitable for the micromanipulation task requirements. In addition, ramp signals are often used as references in micromanipulation instead of step signals. So, such response times are largely sufficient.

\section{Conclusion}

Piezoelectric materials are very prized in micromanipulation due to their rapidity and high resolution. 

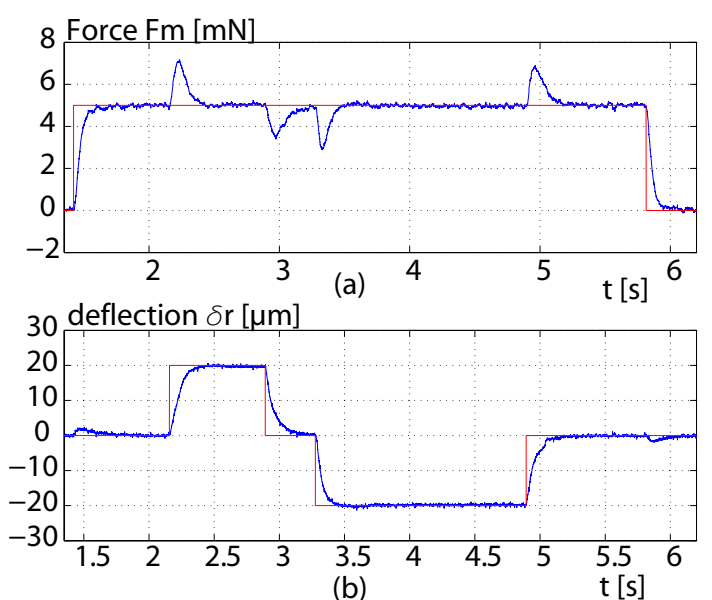

Fig. 12. Experimental results with a rigid plastic mini gear.

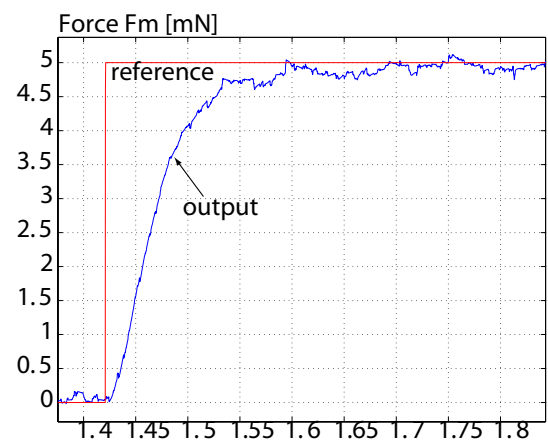

(a) $\mathrm{t}[\mathrm{s}]$

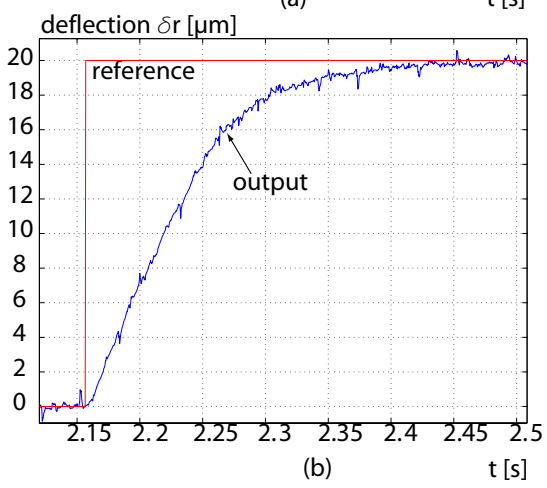

Fig. 13. Step response of each piezocantilever.

One of their application is piezoelectric microgrippers which are based on two piezocantilevers. A microgripper permits the pick-transport-and place of micro-objects with a high positioning accuracy. This paper has presented the modelling and the control of a piezoelectric microgripper dedicated to manipulate micro-objects. Both the positioning and the manipulation force were taken into account. For that, two separated models have been proposed: while one piezocantilever is modelled on deflection, i.e. position, the second is modelled on force. Because the characteristics of the manipulated micro-objects are neglected in the model, the nominal model is subjected to uncertainty. To ensure stability and performances, we have proposed a $H_{\infty}$ controller for each piezocantilever. Whatever the manipulated micro-object characteristics are, good performances suitable for the micromanipulation (disturbances rejection, micrometric positioning accuracy, submillinewton of force accuracy) were obtained in the experiments.

\section{ACKNOWLEDGMENT}

This work is partially supported by the European Project EUPASS (http://www.eupass.org/).

\section{REFERENCES}

[1] Y. Haddab, 'Design and development of a micromanipulation system with force/position control', PhD Thesis (in french), Franche-Comté University, FRANCE, 2000.

[2] P. Ge and M. Jouaneh, 'Tracking control of a piezoceramic actuator', IEEE Transactions on Control System Technology, 4, pp.209-216, 1996.

[3] B. M. Chen, T. H. Lee, C. C. Hang, Yi Guo and S. Weerasooriya, 'An Hinfini almost disturbance decoupling robust controller design for a piezoelectric bimorph actuator with hysteresis', IEEE Transactions on control systems technology, vol.7, $N^{\circ} 2$, Mar 1999.

[4] M. S. Tsai and J. S. Chen, 'Robust tracking control of a piezoactuator using a new approximate hysteresis model', Transactions of the ASME Journal of Dynamic Systems, Measurement and Control, 125, pp.96-102, 2003.

[5] M. Rakotondrabe, Y. Haddab and P. Lutz, 'Plurilinear modeling and discrete $\mu$-synthesis control of a hysteretic and creeped unimorph piezoelectric cantilever', IEEE International Conference on Control, Automation, Robotics and Vision, Singapore December, 2006.

[6] M. C. Carrozza, A. Eisinberg, A. Menciassi, D. Campolo, S. M. and P. Dario, 'Towards a force-controlled microgripper for assembling biomedical microdevices', J. Micromech. Microeng. 10, 271-276. Printed in the UK, 2000.

[7] T. Tanikawa and M. Kawai and N. Koyachi and T. Arai and T. Ide and S. Kaneko and R. Ohta and T. Hirose, 'Force control system for autonomous micro manipulation', IEEE International Conference on Robotics and Automation, pp.610-615, Seoul, Korea, 2001.

[8] C. Liguo and S. Lining and R. Weibinn and B. Xinqian, 'Hybrid control of vision and force for MEMS assembly system', ROBIO, 2004.

[9] M. Gauthier, S. Regnier, P. Rougeot, N. Chaillet, 'Forces analysis for micromanipulation in dry and liquid medi', Journal of Micromechatronics, vol. 3, $N^{\circ} 3-4$, pp. 389-413, september 2006.

[10] J. G. Smits and W. S. Choi, 'The constituent equations of piezoelectric heterogeneous bimorphs', IEEE Transactions on Ultrasonics, Ferroelectrics and Frequency Control, Vol.38, $N^{\circ} 38$, May 1991.

[11] Y. Haddab, N. Chaillet, A. Bourjault, 'A microgripper using smart piezoelectric actuators', IEEE/RSJ International Conference on Intelligent Robots and Systems, IROS'2000, octobernovember 2000, Takamatsu, Japon.

[12] www.piezoceramic.com

[13] T. S. Low and W. Guo, 'Modeling of a three-layer piezoelectric bimorph beam with hysteresis' Journal of MicroElectroMechanical Systems, IEEE, pp.230-237, 4(4), December, 1995.

[14] G. J. Balas, J. C. Doyle, K. Glover, A. Packard and R. Smith, 'ţ-analysis and synthesis toolbox', The Mathworks User's Guide-3, 2001.

[15] K. Glover and J. C. Doyle, 'State-space formulae for all stabilizing controllers that satisfy an $H_{\infty}$-norm bound and relations to risk sensivity', Systems \& Control Letters, vol.11, pp.167$172,1988$.

[16] J. C. Doyle, K. Glover, P. K. Khargonekar and B. A. Francis, 'State-space solutions to standard $\mathrm{H}_{2}$ and $H_{\infty}$ control problems', IEEE Transactions on Automatic Control, AC $34 N^{\circ} 8$, pp.831-846, 1989.

[17] B. C. Moore, 'Principal component analysis in linear systems: controllability, observability and model reduction', IEEE Transactions on Automatic Control, AC-26(1), 1981. 